\title{
O Rap é preto: narrativas e discursos que nos expressam
}

\author{
Eliana Cristina Pereira Santos ${ }^{1}$ \\ Janaína de Jesus Lopes Santana ${ }^{2}$
}

\begin{abstract}
Resumo
Neste trabalho temos como objetivo analisar as narrativas poéticas que entrelaçam o fazer do rap, entendendo que esse faz parte dos três elementos que constitui o Movimento Hip Hop: o rap (música), break (dança) e o grafite / pichação (arte gráfica). Um movimento de expressões de especificidades estéticas musicais, poéticas, de protesto, entre outros ressaltando o que há de genuíno nas produções populares. Para esse trabalho, tomaremos como exemplo para essa análise o Rap: "O Rap É Preto" do MC Nego Max (2018), deste pontuando alguns aspectos linguísticos, sócio históricos e político que são retratados no conjunto da obra. Para essa análise valemo-nos de estudos da antropológicos, educacionais, linguísticos-discursivos. Ou seja, nesse aspecto, ressaltamos a narrativa e os discursos presentes nesse rap que retratam a experiência e escrevivência (Conceição Evaristo, 2014); do MC's (Mestre de Cerimônia); DJ's (Disc-Jóquei); BGIRLS e BBOYS (quem pratica o break). São esses os responsáveis por construir uma conexão entre suas realidades e o público que escuta/ sente, com suas letras que abordam o racismo velado e religioso, gênero e sexualidade, o papel da mulher negra na sociedade e as diversas formas de se entender educação, principalmente uma educação equitativa. Mesmo possuindo uma diversidade interna em suas formas de manifestação artística e política, o Movimento hip hop desde sua raiz vem desenvolvendo um papel de reivindicação política e social e é sobre esta forma de manifestação artístico-cultural que a pesquisa aqui apresentada direciona sua discussão.
\end{abstract}

Palavras-chave: Movimento Hip-Hop; Reivindicação Política; Discursos; Narrativas Cantadas.

\section{Introdução}

Quando eles falam é científico.
Quando falamos é não científico
Universal/específico;
objetivo/subjetivo;
racional/emocional;
imparcial/parcial;

(KILOMBA,2019)

Neste trabalho, temos como objetivo analisar discursivamente as narrativas poéticas que entrelaçam o fazer do rap, entendendo que este faz parte dos três elementos que constituem o Movimento hip-hop: o rap (música), o break (dança) e o grafite/pichação (arte

\footnotetext{
${ }^{1}$ Doutoranda em Letras Universidade Estadual do Oeste do Paraná (UNIOESTE, Campus Cascavel); Pedagoga da Secretaria Estadual da Educação (SEED), Coordenadora e professora do curso de Pedagogia da Faculdade de Foz do Iguaçu (FAFIG). Foz do Iguaçu, Paraná, Brasil, e-mail: eliana.foz@gmail.com

${ }^{2}$ Doutoranda no Programa Interdisciplinar Sociedade, Cultura e Fronteira pela Universidade Estadual do Oeste do Paraná (Unioeste, Campus Foz do Iguaçu), Professora do Curso de Pedagogia da Faculdade de Foz do Iguaçu (FAFIG,) Foz do Iguaçu, Paraná, Brasil. E-mail: ninahh93@ gmail.com
} 
RELACult - Revista Latino-Americana de Estudos em Cultura e Sociedade

Revista Latinoamericana de Estudios en Cultura y Sociedad | Revue Latino-américaine d'Études sur la culture et la société |

gráfica). Tal movimento despontou no Bronx, nos Estados Unidos, em meados da década de 1970, com um encontro singular dos ritmos entrelaçados: jamaicanos, latino-americanos, soul e funk - espalhando-se por diversos países na década de 1980 (SOUZA, 2016) e se adequando de acordo com as diferentes realidades sociais, históricas e culturais.

Tendo em vista que se trata de um movimento de expressões e especificidades estéticas musicais, poéticas, de protesto, entre outros, ressaltando o que há de genuíno nas produções populares, para este trabalho, tomaremos como exemplo a análise do rap: "O Rap É Preto", do MC Nego Max (2018) em parceria com a "Preta Ary", pontuando, portanto, alguns aspectos linguísticos, sócio-históricos e políticos, que são retratados no conjunto da obra.

Para essa análise, valemo-nos de estudos antropológicos, educacionais, linguísticosdiscursivos-literários. Ou seja, nesse aspecto, ressaltamos a lírica presente nesses raps que retratam a experiência e a escrevivência (EVARISTO, 2015); do $M C^{\prime} s$ (Mestre de Cerimônia); DJ's (Disc-Jóquei); BGIRLS e BBOYS (quem pratica o break). São esses os responsáveis por construir uma conexão entre suas realidades e o público que escuta/sente, por meio de suas letras que abordam o racismo velado e religioso, gênero e sexualidade, o papel da mulher negra na sociedade e as diversas formas de se entender educação, principalmente, uma educação equitativa.

Ao focar nas narrativas poéticas presentes nas rimas de rap, é importante ressaltar as especificidades presentes em cada letra, absorvendo os anseios culturais do território que foi produzido e de quem o produz, assim, essa expressão popular torna-se uma importante ferramenta de denúncias sociais.

Sendo assim, ao analisarmos as rimas presentes no rap, vale ressaltar a formação linguística das letras, uma vez que o rap é entendido como ritmo e poesia, essa poesia gingada, dançada que evidencia uma "escrevivência" (EVARISTO, 2015) discriminada e embranquecida questionadora do processo de embranquecimento da história, "escrevivênciando" outras faces, conforme apontado no seguinte trecho: "Escurecer essa zorra, nóis no topo da gangorra/Bagunçaram nossa história deixa que os pretos discorra", discorrendo um escurecimento da história com protagonismo preto, desconstruindo a afirmação de uma democracia racial nacional, trazendo à tona os diversos conflitos e revoltas que tivemos no processo de resistência contra a escravização e após a falsa abolição da escravatura.

Mesmo possuindo uma diversidade interna em suas formas de manifestação artística e política, o Movimento hip-hop, desde sua raiz, vem desenvolvendo um papel de reivindicação 
RELACult - Revista Latino-Americana de Estudos em Cultura e Sociedade

Revista Latinoamericana de Estudios en Cultura y Sociedad | Revue Latino-américaine d'Études sur la culture et la société |

política e social e é sobre esta forma de manifestação artístico-cultural que a pesquisa aqui apresentada direciona sua discussão.

\section{RAP: Qual a sua história?}

O movimento formado por jovens, que veio para gingar as/e nas estruturas, foi impulsionado no Bronx, na cidade de Nova York - Estados Unidos, na década de 1970 (SOUZA, 2016, p. 47), trazendo a ancestralidade dos ritmos jamaicanos, do soul, funk, cumbia, salsa e Jazz. Ele se desenvolve em meio às conturbações políticas e sociais, carregando bandeiras de luta dos afro-latino-americanos e caribenhos por uma sociedade mais justa e antirracista.

Com suas batidas Graves e rimas cortantes, disseminou-se pelo mundo a partir da década de 1980, assim, o movimento hip-hop é constituído por três elementos principais: o rap (música), o break (dança) e o grafite/pichação (artes gráficas) ${ }^{3}$. No contexto social de crianças e jovens entrando cada vez mais cedo em gangs e crimes, o rap, o grafite/pichação e o break surgiram como alternativas para externalizar suas revoltas, indignações e anseios (HERSCHMANN, 1997, p. 201). Como colocado por Hall (1996, 2011), a produção musical pode ser entendida como um fazer cultural, assim como o soul e o funk foram ressignificados como expressões para posicionamentos políticos e sociais da população periférica.

No Brasil, o Movimento hip-hop tomou força no início da década 1980, (PIMENTEL, 1999, p. 14) tendo como ponto de partida a "Terra de Arranha Céus" (Racionais $M C$ 's). Tais encontros iniciaram em São Paulo com dançarinos, rimadores e grafiteiros/pichadores, fazendo das ruas do centro da cidade o palco para as artes da Periferia. Um dos primeiros grupos de rap a ser reconhecido em âmbito nacional foi o MC Thaíde e DJ Hum, posteriormente surgiu o grupo Racionais $M C$ 's, formado por Mano Brown, Edy Rock, Ice Blue e KL Jay, sendo assim, com esse reconhecimento, evidencia-se como algumas rimas de rap fazem referência a narrativas e/ou discursos emblemáticos desses grupos.

No rap, corpus do artigo, afirma-se "Por isso que eu vim da selva sou gorila e piso em hamster" fazendo referência à letra "Negro Drama" do Racionais $M C$ 's. Com isso, nota-se a construção de narrativas (viés antropológico) e dos discursos (viés discursivo pecheutiano) que entrelaçam diversas referências para a construção de uma narrativa/ou um discurso que (rap)ense a história preta e o processo de invisibilização permanente. Esse rap é entendido

\footnotetext{
${ }^{3}$ Alguns autores entendem o Movimento hip-hop com quatro elementos, inseri o MC (Mestre de Cerimônia) nesta
} divisão. 
RELACult - Revista Latino-Americana de Estudos em Cultura e Sociedade

Revista Latinoamericana de Estudios en Cultura y Sociedad | Revue Latino-américaine d'Études sur la culture et la société | Latin American Journal of Studies in Culture and Society V. 07, $\mathrm{n}^{\circ}$ 01, jan.-abr., 2021, artigo $\mathrm{n}^{\circ} 2078$ | claec.org/relacult | e-ISSN: 2525-7870

como a expressão musical que embala a possibilidade de novas construções de identidade e a valorização de culturas populares/africanas e afrodescendentes, como o samba, o samba rock, samba de roda, embolada, forró, entre outros.

Tanto no Brasil como nos EUA as populações negras vivenciaram disputas por direitos e resgate/construção de identidades, entre os quais estão as discussões pelos direitos civis, na década de 1960 nos EUA. Nesse ambiente, o Movimento hip-hop possibilitou a conexão com o movimento negro, mesmo apresentando demandas e trajetórias particulares.

Assim, cada rima de rap traz a especificidade regional do lugar, ao mesmo tempo em que se entrelaça com um contexto mais amplo entre o Povo Preto, conforme expresso neste trecho: “Ouvi dizer que o rap não tem cor, o rap é preto! ”. Quando esse estilo musical ganha notoriedade, por exemplo, vira "mercadoria", pois a mídia, enquanto indústria cultural, tenta abarcar esse nicho mercadológico e embranquecer as rimas. Por outro lado, temos focos de resistência dentro do movimento hip-hop pelo uso de narrativas poéticas presentes nas rimas para dar "o papo reto" construindo possibilidades de escurecimentos de memórias coletivas, tendo como fio condutor a Literatura Marginalizada (VAZ, 2008), partindo da vivência periférica de modo a ressignificar o conceito de Negritude no âmbito individual que deságua para a esfera coletiva.

O antropólogo e professor Kabengele Munanga (2008) nos apresenta a relevância da retomada da aprendizagem da história individual e comunitária que possibilita ao sujeito sentir-se pertencente a uma/sua sociedade, sendo o movimento hip-hop atrelado ao movimento negro importantes para a desconstrução histórico-social do povo preto, evidenciando as lutas e conquistas dessas populações na estruturação dessa nação. Esse autor também destaca a cultura popular, por exemplo o Movimento hip-hop e o rap, como ponte para outras formas de se fazer saber, ressaltando o protagonismo da ancestralidade da cultura Negra nesse fazer identidade. Ao escutar a rima "Mas hoje os Preto é um campo minado/Se pisar, explode/Então segura que agora é nóis" ressalta-se o termo "Preto" no processo de reafirmação identitária, explicitando sua origem nas lutas antirracistas pelos gritos de ordem, a exemplo "Black is Beautiful" e "Black Power", usados pelo Partido dos Panteras Negras ${ }^{4}$ e pelo Movimento Negro Unificado (MNU) ${ }^{5}$.

\footnotetext{
${ }^{4}$ O Partido dos Panteras Negras foi fundado em 1966, nos Estados Unidos. Esse movimento social tinha como principal bandeira a luta antirracista pela qual promovia práticas diretas com a comunidade objetivando a conscientização.

5 O Movimento Negro Unificado (MNU) foi criado em 1978, no Brasil, tendo como algumas propostas a educação para as relações étnico-raciais e a emancipação do Povo Preto Brasileiro.
} 
RELACult - Revista Latino-Americana de Estudos em Cultura e Sociedade

Revista Latinoamericana de Estudios en Cultura y Sociedad | Revue Latino-américaine d'Études sur la culture et la société |

Consoante a antropóloga Autor (2xxx, p.12), “com letras que retratam a realidade na qual o rap foi construído, nas experiências vivenciadas dos $M C^{\prime} s$, DJ's e BBOYS - que tecem uma conexão entre suas vivências e o público que os assistem”, ou seja, o movimento hip-hop proporciona o aquilombamento (NASCIMENTO, 1980) de memórias e escurecimento da história reafirmando a trajetória do processo diaspórico do Povo Preto e revertendo a lógica escravizadora, como apresentado no trecho: "Pra pegar o que nos tiraram e agora nóis tá com pressa/Linha de Rei e Rainha, Curandeiro, Guerreiro".

Ao evidenciar a construção do imaginário da nação e das identidades brasileiras que surgem na diáspora, torna-se necessário definir este conceito, que é proposto pelo sociólogo jamaicano Stuart Hall (1996, p. 75) da seguinte forma:

\footnotetext{
não é definida por pureza ou essência, mas pelo reconhecimento de uma diversidade e heterogeneidade necessárias; por uma concepção de 'identidade' que vive com e através, não a despeito, da diferença; por hibridização. Identidades de diáspora são as que estão constantemente produzindo-se e reproduzindo-se novas, através da transformação e da diferença.
}

Foi pelo processo de hibridização que as américas foram formadas culturalmente, resultado de processos coloniais, indígenas, africanos e europeus. Essa diversidade e dinamicidade cultural, mesmo sendo fruto da colonização, possui uma dinamicidade ímpar, um estar "sempre já-fundido, sincretizado com outros elementos culturais" (HALL, 1996, p. $74)$.

Assim, práticas estético-musicais como o rap, por exemplo, propiciam a reconstrução histórica da população negra no mundo de diáspora, refletido não somente pela sonoridade, mas pela forma de escrita desse rap, tal qual é apresentado ao público que o escuta, através de uma performance estética nas vestimentas, no falar e na linguagem corporal, que rimam outras interações responsáveis por fazerem a ponte entre um rap latino-americano ao Continente Africano. Desse modo, há uma costura com a ancestralidade por intermédio de um processo de Atlânticos Negros (GILROY, 1993) revelador de significados que podem ser usufruídos nas interações que dizem respeito ao fazer ações políticas e socioculturais.

Para o autor Domingues (2007), o Movimento hip-hop representa uma forma visionária dentro do Movimento Negro, pelo seu poder de difusão nacional, alcançando camadas populares e contribuindo para o (rap)ensar com a linguagem periférica, tendo como fio condutor o debate para a ressignificação da construção histórica atribuída ao signo "raça". Sendo assim, ao ressignificar a raça 


\begin{abstract}
O movimento negro indaga a própria história do Brasil e da população negra em nosso País, constrói novos enunciados e instrumentos teóricos, ideológicos, políticos e analíticos para explicar como o racismo brasileiro opera não somente na estrutura do Estado, mas também na vida cotidiana das suas próprias vítimas. Além disso, dá outra visibilidade a questão étnico-racial, interpretando-a como trunfo e não como empecilho para a construção de uma sociedade mais democrática, onde todos, reconhecidos na sua diferença, sejam tratados igualmente como sujeitos de direitos (GOMES, 2012, p. 731).
\end{abstract}

Nesse sentindo, quando o rap traz o debate étnico-racial para esferas mais amplas como nos bairros periféricos, afirmando que é compromisso (SABOTAGEM, 2000), desempenhando o comprometimento nas formulações de ações que superem as desigualdades raciais e sociais, ressignificando o conceito de raça como algo emancipatório, o movimento hip-hop proporciona, portanto, o (rap)ensar ao remixar no Pretuguês (GONZALEZ, 1988) lutas e conquistas do povo preto. A autora afirma que "o caráter tonal e rítmico das línguas africanas trazidas para o Novo Mundo, além da ausência de certas consoantes (como o I ou o R, por exemplo)" (GONZALEZ, 1988, p. 70) são influências do povo negro na formação de novas palavras e, também, podemos considerar um processo de resistência.

Lélia Gonzalez (1984) afirma que muitos não compreendem o jeito de falar essas palavras, "é engraçado como eles gozam a gente quando a gente diz que é Framengo" (GONZALEZ, 1984, p. 238) ". Atualmente, poderíamos afirmar que não passa de preconceito linguístico e continua "chamam a gente de ignorante dizendo que a gente fala errado. E de repente ignoram a presença desse $\mathrm{r}$ no lugar do 1 nada mais é que uma marca linguística de um idioma africano" (GONZALEZ, 1984, p. 238). Ou ainda, "o lugar discursivo e disciplinar de onde as questões de identidade são estratégica e institucionalmente colocadas" (BHABHA, 2014, p. 89).

Trazendo, então, para a análise das Rimas do "O Rap É Preto" fica evidente o quanto o contexto social e histórico dos dois MCs", Nego Max" e "Preta Ary", costuram-se com a construção do passado histórico do Povo Preto, em que a narrativa presente no rap afirma a trajetória de luta e resistência nos trechos, rimas, ou sequências discursivas, como entende a Análise de Discurso pecheutiana, doravante AD.

\title{
3 O RAP tem cor: É PRETO
}

Ao compreender-se narrativas cantadas enquanto definições antropológicas, etnográficas, pode-se afirmar que as características dessas narrativas, desses dizeres são 
RELACult - Revista Latino-Americana de Estudos em Cultura e Sociedade

Revista Latinoamericana de Estudios en Cultura y Sociedad | Revue Latino-américaine d'Études sur la culture et la société |

dotadas de especificidades e que estas são dadas, a priori, pelo pertencimento cultural, uma vez que constrói e é construída pelo passado. Em (HALL, 2011, p. 50, aspas do autor) a cultura denominada de marginalizada possibilita a mudança social, como se abrirem brechas, resultado "do histórico de lutas e reivindicações em torno do direito à existência de " diferentes diferenças' [...] enfrentamentos entre [...]dominantes e dominados” e, dessa maneira, vão se inserindo novos sentidos que quebram com a "“hegemonia cultura"”.

Se tomar essas narrativas enquanto discursos, dentro da $\mathrm{AD}$ pecheutiana, pode-se compreender vários outros elementos discursivizados na forma de efeitos de sentidos, condições de produção, memória discursiva, entre outros conceitos que nos permitem analisar essa canção, tendo em vista que "um discurso é sempre pronunciado a partir de condições de produção dadas" (PÊCHEUX, 1993. p. 77). A canção/rima é uma composição do "MC Nego Max" em parceria com a "Preta Ary", integrante do grupo "D’Origem", ambos pretos.

Começando pelo título da canção, a afirmação "O Rap é preto", além de se tratar do título, produz efeitos de sentidos e significações em cada palavra, em cada verso, elencando uma construção imagética da contribuição do povo preto que passou pela diáspora, foi escravizado e escancaradamente roubado culturalmente, ou seja, apropriaram-se de suas formas de resistência, apresentando-as de maneira embranquecida, tomemos como exemplo: o rock.

Ao fazer uma pesquisa nas redes sociais sobre o representante do rock, tem-se como nome Elvis Presley, ou toda uma Europa roqueira com bandas desde os Beatles. Entretanto, esse gênero musical, uma influência do gospel com blues e outros gêneros da época, foi gravado pela primeira vez por uma mulher negra, Rosetta Tharpe ${ }^{6}$, na década de 1940. Ela foi a única a misturar os gêneros musicais e utilizar uma guitarra elétrica. Poucas são as pessoas que sabem disso, pois as narrativas poéticas passam por um processo de apagamento, são discursos silenciados e apropriados pelo não preto. Assim, quando o MC Nego afirma que o rap é preto, os efeitos de sentidos estão em demarcar territorialmente esse gênero musical, uma tentativa de impedir a apropriação de uma cultura afro, ou seja, dizer aos brancos que podem, sim, cantar rap, mas referenciar o lugar de onde essas batidas e ritmos surgiram, "o sentido das palavras em um discurso remete sempre a ocorrências anteriores" (POSSENTI, 2005, p. 373).

\footnotetext{
${ }^{6}$ Nascida Roseta Nubin em Cotton Plant, Arkansas, 1915, in Revista Rolling Stones de 13 de dezembro de 2017. Disponível em: : https://www.rollingstone.com/music/music-features/why-sister-rosetta-tharpe-belongs-inthe-rock-and-roll-hall-of-fame-123738/ Acesso em: 30/11/2020.
} 
RELACult - Revista Latino-Americana de Estudos em Cultura e Sociedade

Revista Latinoamericana de Estudios en Cultura y Sociedad | Revue Latino-américaine d'Études sur la culture et la société |

Há um entrecruzamento entre passado e presente afirmado a todo instante isso é preto, sem buscar a inferiorização, sem seguir "um entendimento de que tudo que é bom e bonito não pode ser preto" (WILLIAM, 2019, p. 37), ou seja, contrariando a demarcação que historicamente houveram determinações articuladas discursivizando que ser preto não seria bonito, aceitável, devido a todas as condições de escravização e tentativas de inferiorização que, por outro lado, por meio da resistência, busca não repetir o que aconteceu com o rock.

O lexema preto na canção discursiviza a positividade, a "resistência ontológica" (FANON, 2008, p. 104). Vem justamente na contramão de qualquer negatividade ou inferiorização que a semântica histórica quer impor. Parafraseando Fanon (2008, p. 108) afirmar-se preto é fazer-se conhecer, conforme afirma a canção "pode se alegrar que agora a coisa ficou preta", ao mesmo tempo em que nessa rima há a positividade em oposição à negatividade que historicamente foi atribuída ao povo preto. Ainda hoje há uma expressão "a coisa ficou preta" para se referir a algo que esteja, de certo modo, ruim. Contudo, quando a rima afirma "a coisa ficou preta" antecedendo no verso "pode se alegrar", faz com que esses sentidos negativos se transformem em positivos e, por consequência, em movimento de resistência. Em outras palavras, se a expressão sempre foi utilizada para os sentidos negativos, do ruim, das coisas sem solução, inclusive há uma canção sertaneja que afirma "a coisa tá preta, a coisa tá feia" (1983) interpretada por "Tião Carreiro e Pardinho"7, alimentando um imaginário social sobre o que seja preto seja inclusive feio. No entanto, vem a rima de um MC reconfigurando e invertendo sentidos já colocados, ou seja, ressignificando para positivo aquilo que já estava estabelecido, se “a coisa está preta” é porque está ótimo, por isso é motivo de festejar, ficar feliz, alegre.

Sentidos ressignificados que a rima diz à origem do povo negro, diferente de falar em escravização, afirma que as origens são "linha de Rei e Rainha, Curandeiro, Guerreiro", quatro personalidades de grande importância durante a Idade Média em cada reino: governança, a arte da cura física ou mental e o lutador, que são os guerreiros. Em termos de classe social, há que se situar que os sentidos são as pessoas que tinham importância dentro de suas comunidades, não necessariamente, como, hoje, ocupantes da classe trabalhadora mais explorada.

\section{Tentativas de análises: os sentidos em rimas}

\footnotetext{
${ }^{7}$ Disponível em: https://www.letras.mus.br/tiao-carreiro-e-pardinho/81667/ Acesso em: 25/11/2020.
} 
RELACult - Revista Latino-Americana de Estudos em Cultura e Sociedade

Revista Latinoamericana de Estudios en Cultura y Sociedad | Revue Latino-américaine d'Études sur la culture et la société | Latin American Journal of Studies in Culture and Society V. 07, $\mathrm{n}^{\circ}$ 01, jan.-abr., 2021, artigo $\mathrm{n}^{\circ} 2078$ | claec.org/relacult | e-ISSN: 2525-7870

Na rima, "Autoestima minada/Por mentes contaminada/Mas hoje os Preto é um campo minado/Se pisar, explode" o sentido de baixa autoestima traz para o fio do discurso todos os discursos racistas e de atitudes que "contaminaram as mentes", que fizeram com que, mesmo sendo em grande quantidade populacional, o povo preto sempre tivesse sua representação e representatividade minorizada. Entretanto, adverte que, depois de tanta luta e resistência, a população negra vem compreendendo como funciona o sistema sociocultural, estudando sua história, empoderando-se de conhecimento e por isso compara com "um campo minado", ou seja, não dá pra saber quanto um negro sabe em relação aos seus direitos de existência, não dá mais para compreender "que os negros são ignorantes".

A cada nova geração que nasce começam a compreender a história de luta de um povo que foi escravizado, mas que nunca deixou de resistir, novas gerações que ouvem novas histórias, não mais a história contada pelo branco, mas com muito mais significância a história do seu povo, que permitiu a sua existência, as leis que foram conquistadas, a necessidade de cada dia mais aprender sobre si.

Na rima "agora nóis tá com pressa", quer pela consistência ou persistência, o povo preto, devido à própria movimentação histórica sempre vivendo a pressão, foi atraindo e provocando reflexões, não só das lutas contra a discriminação racial, mas de toda a situação de desigualdade social, fruto da desigualdade racial, do apoio da esquerda política brasileira que em conjunto escreveu um documento ${ }^{8}$ para exigir do governo elementos, a fim de superação do racismo e, principalmente, um ministério junto ao Governo Federal que trabalhasse em função da luta antirracista, reforçada pelas pesquisas do Instituto Economia Aplicada (IPEA). Desse modo, várias políticas públicas foram aprovadas e deram continuidade à historicidade de implementações e aplicações fazendo com que as conquistas e resistências se materializassem, desde o início das inquietações de mudança. Por isso, "nóis (povo preto) tá com pressa", afinal, já foram séculos de lutas, resistências e reinvindicações. Uma pressa de mudança na formação social a qual produz efeito da história, uma pressa para a equidade de direitos, de reparação histórica.

Considerando que historicamente os cargos de poder foram ocupados em sua maioria por homens brancos, temos "pressa", sim, "pra pegar o que nos tiraram". Nas palavras de Willian (2019, p. 35), "sequestraram produções ou traços de uma cultura subjugada e

\footnotetext{
8 Programa de Superação do Racismo e da Desigualdade Racial "Institui Grupo de Trabalho, outro Interministerial, com a finalidade de desenvolver políticas para a valorização da População Negra e dá outras providências", em 20 de novembro de 1995 (Governo presidencial Fernando Henrique Cardoso). Disponível em:

http://www.planalto.gov.br/CCIVIL_03/DNN/Anterior_a_2000/1995/Dnn3531.htm\#textoimpressao. Revogado em 2019 pelo Decreto 10.087/2019 pelo atual presidente do Brasil Acesso em: 25/11/2020.
} 
RELACult - Revista Latino-Americana de Estudos em Cultura e Sociedade

Revista Latinoamericana de Estudios en Cultura y Sociedad | Revue Latino-américaine d'Études sur la culture et la société |

dotaram-nos de maneira descontextualizada para tirar proveito daquilo que consideram interessante, e ignorando os significados reais desses elementos", ou seja, aqui temos a definição de apropriação cultural. Essa definição só se aplica quando há um esvaziamento de toda uma cultura de luta e pertencimento dos elementos e são utilizados de maneira descontextualizada, além de não referenciar o pertencimento. Muitas coisas foram tiradas dos povos escravizados, assim o rapper afirma que queremos novamente a história preta de luta e resistência, moradias dignas, direito a empregos não subalternizados, direito à educação e ao acesso equitativo a esses espaços, respeito pela Arte preta, pela religiosidade, enfim pela diferença que nos faz equitativos em direitos, sem ter que se calar diante de qualquer desvalorização, estigmatização, sentidos que foram silenciados em vários aspectos (ORLANDI, 1997) e deslocados para um lugar europeu, branco como a cor do esquecimento.

Ao mesmo tempo em que ocorreu a emolduração eucentralizada, também aconteceram reações advindas, principalmente, dos Movimentos Negros e das escolas. Sim, daqueles professores que ressignificam os saberes estabelecidos nos livros, com a valorização de outras histórias, dos próprios estudantes que têm sua história. Já dizia o próprio Pêcheux (1969), os sentidos estão muito longe do óbvio que se apresenta entre a língua e as coisas do mundo, eles são uma construção dada pelas Histórias (principalmente aquela não contada) e para o sujeito que é interpelado pela ideologia.

E a rima continua "pronto no fronte pra enfrentar quem fala que nóis não pode", pronto para defender os componentes culturais pretos contra depuração, banalização ou esvaziamento, "um campo minado, pronto pra explodir". Nesse sentido, há o atravessamento imprescindível da educação para relações étnicas raciais com práticas freirianas emancipadoras, que têm armado o povo preto para enfrentar como "guerreiro" "no fronte" discursos que tentam deslegitimar as conquistas e os saberes diaspóricos de ancestralidade. De modo que, inclusive, acontecem "batalhas de rap" nesse mundo artístico, nas quais, por meio das palavras, os cantores trazem à baila diversas discussões sobre a luta e resistência do povo. Sentidos sobre "pronto pra explodir" discursivizam o fato de os negros terem voz, seja pelos movimentos, ou por uma rede de apoio de outros negros prontos para defender os seus, diferentemente de outrora onde eram silenciados e se silenciavam diante de injustiça, maustratos. Embora, "não nos ensinaram a amar/nos ensinaram a matar", entretanto, estrategicamente o povo preto aprendeu a se defender e começou a se proteger similar a um conto de Conceição Evaristo (2015, p. 99), cujo título é “A gente combinamos de não morrer". 
RELACult - Revista Latino-Americana de Estudos em Cultura e Sociedade

Revista Latinoamericana de Estudios en Cultura y Sociedad | Revue Latino-américaine d'Études sur la culture et la société |

Voltando à "ao fronte", front, ou frente, "pronto pra quem fala que nóis não pode" traz ao fio do discurso, também, sentidos de como perante a uma guerra, estrategicamente bem colocados, as batalhas que a vida foi trazendo uma a uma, e os negros foram ganhando terreno, conquistando cada um dos espaços, estão, agora, "pronto" no seu "lugar de fala" (RIBEIRO, 2017) para defender com argumentos verbais àqueles que dizem "negro não pode". Seu principal argumento é o conhecimento de sua história e as leis que regem seu país. Ou seja, "há uma mudança na qual o poder visita outro locus de enunciação, (re)significa a cultura, (re)constrói a memória daqueles que estavam em situação de invisibilidade social e cultural e altera o imaginário nacional" (MIRANDA, 2011, p. 1), como na rima "bagunçaram nossa história, deixa que os preto discorra" ou "chegou a nossa vez, fique de boa e não se meta".

Segundo Tella (1999, p. 60), a partir do final dos anos 1980 o rap passa a referenciar ao passado da população negra até os problemas que enfrentam atualmente, "mostra importância da religião afro, resgata datas históricas, heróis, movimentos de direitos civis, artistas e personagens, como Marter Luther King Jr, Movimento Black Power, Nelson Mandela, Black Panthers [...] Zezé Mota, Zumbi, Benedita da Silva”. Ou seja, a galera, não “apenas" fazia rima, mas eram necessárias leituras para saber do processo de escravização, também estar "pronto" com saberes e conhecimentos dos líderes brasileiros e estadunidenses, uma vez que as situações dos negros são iguais nos dois países. Mas no Brasil o combate é mais difícil, pois perpassa por um discurso de negação de existência da falsa democracia racial.

Discursivamente, Lélia Gonzalez (1984), há quarenta anos, fazia essa reflexão a respeito da língua, uma reflexão sobre os usos coloquiais de algumas formas do português brasileiro. No Brasil, existem grupos de pessoas que falam dessa maneira, essa troca do L pelo $\mathrm{R}$ é um fenômeno denominado rotacismo. "Ao mesmo tempo, acham o maior barato a fala dita brasileira, que corta os erres dos infinitivos verbais que condensa você em 'cê', o está em 'tá' e por aí afora. Não sacam que estão falando pretuguês" (GONZALEZ, 1984, p. 238). Assim, quando encontramos na rima "tamo/nóis/memo/neguim/reaça" são palavras que manifestam a transformação na formação sócio-histórico e cultural do povo preto, não só lugar de formação, mas de resistência. Sendo assim, ao serem utilizadas nas rimas, a linguagem traz a representatividade pela qual outro preto se reconhece e compreende os dizeres, ao mesmo tempo em que traz interdiscursivamente quem são as pessoas que utilizam essa forma de falar: são descendentes de escravizados, indígenas, moradores das periferias, que formam a base da pirâmide econômica social, ou seja, a classe trabalhadora. Vale 
RELACult - Revista Latino-Americana de Estudos em Cultura e Sociedade

Revista Latinoamericana de Estudios en Cultura y Sociedad | Revue Latino-américaine d'Études sur la culture et la société |

ressaltar que o português não foi a primeira língua brasileira, os primeiros colonizadores aprenderam os idiomas indígenas.

Essa linguagem é fruto de aspectos históricos da colonização brasileira, já que, se o rap nasce nas periferias, não teria melhor linguagem de narração nas rimas. Essa língua é um elo do local, para estabelecer conexões com a população. Inclusive as gírias, os palavrões, são elementos linguísticos do cotidiano. A formulação "O rap não tem cor é o caralho" carrega efeitos de sentidos da violência que o povo preto sofre no dia a dia. Nas palavras de Miranda (2011, p. 1), "são vozes plurais que emergem das margens do poder estabelecido e lutam pela construção da cultura periférica, buscando reformular o discurso ignorado pela história excludente", portanto, a rima em que aponta que se trata da "minha arma. Raiz e estrutura", reverbera a necessidade de marcar esse espaço que "o rap é preto!".

Hoje o que se tem são as línguas gerais faladas pelo território brasileiro. Já tivemos as línguas da costa brasileira, as misturas do português com as línguas indígenas, depois é que vieram as línguas dos africanos, dos mais variados países. Somente com o período pombalino que o Brasil, enquanto colônia, foi obrigado a extirpar as línguas dos indígenas e falar somente o português. Sendo assim, o Brasil nasceu de um multilinguismo, lembrando que havia um contingente grande que não era escolarizado, dessa forma não falavam o português luso, assim, a língua portuguesa falada no Brasil é o reflexo das questões étnicas. Mesmo o português luso é descendido do latim, como as línguas: francesa, espanhola e italiana. Por exemplo: a palavra brasileira, que hoje é dita como "igreja", também é dita de outras formas, tais como no latim "Ecclesia", no francês "église" no espanhol "Iglesia". Esse exemplo é só para perceber as possibilidades da língua. Na teoria pecheutiana, o autor compreende a língua como base material para os processos discursivos, ou seja, é essa língua pretuguesa que produz, reproduz ou transforma as relações dos modos de produção social, provocando a determinação das próprias relações da sociedade (HERBERT/PÊCHEUX, 2011[1966], p. 4) ou, ainda, nas palavras de Orlandi $(2007$, p. 7) a "linguagem de um processo discursivo bem mais abrangente e é assim que deve ser considerado. Ele é um exemplar do discurso", "Ouvi dizer que o rap não tem cor/o rap é preto/não tem cor é caralho".

Cabem aqui dois elementos a serem ressaltados: a linguagem com palavrões e o rap e a relação de gênero feminino, entretanto esses dois aspectos serão abordados em um outro artigo mais completo. No início do rap brasileiro, podemos destacar como gênero feminino Negra Lee (Universal Music, 2004); Nega Gizza e Dina Dee (noiva do Thock, TNT Records, 2003), eram apenas essas mulheres que tinham vendagens como rappers diante do universo extremamente masculino, sexista e patriarcal. Nos dias atuais, são muitas $b$-girls que fazem e 
RELACult - Revista Latino-Americana de Estudos em Cultura e Sociedade

Revista Latinoamericana de Estudios en Cultura y Sociedad | Revue Latino-américaine d'Études sur la culture et la société |

vivem das rimas. Há que se lembrar que as mulheres talvez não estivessem em lugar de destaque, mas sempre foram elas as parceiras dos "manos" que faziam rap, porém "a supremacia masculina perpassa todas as classes sociais, estando também presente no campo da discriminação racial" (SAFFIOTI, 1987, p. 16).

Neste trabalho, tem-se "Preta Ary" que começa suas rimas assim "pode se alegrar que agora a coisa ficou preta”, essa rima, nas condições de produção apresentadas, é elemento positivo, uma busca de reconstrução da linguagem brasileira para uma perspectiva antirracista, ou seja, um letramento racial para que a desconstrução da linguagem sexista, racista e homofóbica seja feita. A exemplo da urgência dessa desconstrução, tem-se as formulações "denegrir" e "serviço de preto", ambas carregadas de sentidos negativos em relação à população preta. A definição de letramento racial perpassa por práticas de leituras que incluem produções negras, com reconhecimento simbólico e material do racismo como problema social, ser antirracista e o reconhecimento social dos privilégios da branquitude, entre outros conjuntos de elementos que fazem parte desse conceito.

E, assim, continuam defendendo um lugar do feminino, feminista preta, "Preta Ary" rima "E o rap é as Preta/Mexeu com nóis é treta/é rap de buceta dando a letra/na postura e na caneta", é fundamental apontar o uso dos palavrões, palavras obscenas, grosseiras, principalmente advindas de uma mulher que, segundo as "leis que controlam tanto a circulação dos discursos quanto dos falantes" (POSSENTI, 1998, p. 145).

Nas palavras de Santos (2010), as rimas com as palavras: caralho/porra/não cague/buceta se valem de sentidos poéticos nos quais

\begin{abstract}
A obscenidade é uma forma de transgressão moral que tem função político-social, uma vez que exerce uma crítica corrosiva às estruturas culturais e morais da sociedade brasileira. A tematização de opções sexuais diferentes, escandalosas, prazeres vergonhosos, devassidão, é mais um modo que os poetas encontraram para denunciar o falso moralismo da sociedade conservadora, que se choca com o sexo e o palavrão, mas permanece indiferente diante de tortura, censura, violência urbana, miséria, corrupção, guerras e outras barbáries (SANTOS, 2010, p. 92-93).
\end{abstract}

Vale lembrar que a língua padrão tem traços do colonizador, da branquitude, porque na linguagem padrão oficial é a língua do poder e nessa linguagem são silenciadas quaisquer questões linguísticas que fujam da norma. O rap, nesse sentido, não vem para padronizar, muito pelo contrário, vem para pôr o dedo na ferida, nem que necessite utilizar de palavras sem a "higienização" linguística. Trata-se, assim, da estimulação do rompimento com os padrões sociais, uma resistência à norma, uma forma de chocar com os discursos poéticos conservadores. 
RELACult - Revista Latino-Americana de Estudos em Cultura e Sociedade

Revista Latinoamericana de Estudios en Cultura y Sociedad | Revue Latino-américaine d'Études sur la culture et la société |

Ainda deixa um recado para todos aqueles que não são e vão viver como rappers "Só tenha respeito e por favor não estrague a minha cultura", quando pede respeito, traz efeitos de pedidos para que jamais esqueçam de onde nasceu e como nasceu o rap enquanto gênero musical, para que ao fazê-lo respeite-se toda a ancestralidade, toda a religiosidade que faz parte culturalmente do povo preto. O respeito também traz efeitos de sentidos de "não se aproprie" apenas do rap, não o torne um monte de rimas mercadológicas, uma vez que cada um dos raps tem uma narrativa de pertencimento de um grupo de pessoas de um determinado lugar, os sentidos de pertencimento e histórias de vidas são discursivizados em cada rima.

\section{CONSIDERAÇÕES FINAIS}

Nesse artigo, buscou-se apresentar uma pequena amostra da análise das condições de produção das rimas do MC "Nego Max" e da "Preta Ary" em relação à necessidade de demarcar a territorialidade de onde e como se originou o rap. Uma posição afirmativa da cor do rap. Fica assim entendido que o "Rap é preto", seus elementos de construção são narrativas poéticas que partem de uma memória histórica sobre o processo de colonização brasileira.

Assim, as narrativas discursivizadas expressam a ligação direta do rap com o processo diaspórico, seja por meio da ancestralidade dos ritmos latinos americanos e caribenhos, pelas pautas políticas antirracistas dos afro-latino-americanos e caribenhos ou/também pelo falar com o Pretuguês, letramento racial, feminismo negro, do lugar de fala, branquitude e educação antirracista.

Nesse sentido, o rap vem como uma resposta por intermédio da manifestação artísticocultural, principalmente ligada à parcela jovem e periférica da população, para os processos históricos, ressignificando, nas batidas e na corporalidade, o que é dito como "Coisa de Preto", com reivindicações sociais políticas. Ressaltando o quanto o lugar de fala é determinante para o se fazer rap, com as vivências dos/das $M C$ 's que recontam as outras faces da história e escurecem as memórias do povo preto.

O rap aqui pode ser entendido como um elemento além da musicalidade, como narrativa e discursos, baseada na escrevivência periférica que redefine visões sobre racialidade, classe e gênero, provocando a reflexão do processo do racismo, expropriação, exploração e a apropriação de alguns elementos da Cultura Afro-latino-americana e Caribenha. 
RELACult - Revista Latino-Americana de Estudos em Cultura e Sociedade

Revista Latinoamericana de Estudios en Cultura y Sociedad | Revue Latino-américaine d'Études sur la culture et la société |

\section{REFERÊNCIAS}

BHABHA, Homi K. O local da cultura. $2^{\mathrm{a}}$ ed. $1^{\mathrm{a}}$ reimpressão. Tradução de Myriam Ávila, Eliana Reis e Gláucia Gonçalves. Belo Horizonte: Editora da UFMG, 2014.

DOMINGUES, Petrônio. Movimento negro brasileiro: alguns apontamentos históricos. Revista Tempo ,12.23, 2007: 100-122.

EVARISTO, Conceição. Olhos d'água. Pallas Editora, 2015.

FANON, Frantz. Pele negra, máscaras brancas. Salvador: EdUfba, 2008.

GILROY, Paul. O atlântico negro. São Paulo: Editora 34, 1993.

GOMES, Nilma Lino, Movimento Negro e Educação: ressignificando e politizando a raça, Educação \& Sociedade. Campinas, v. 33, n. 120, p. 727-744, jul. a set. 2012. Disponível em https://www.scielo.br/pdf/es/v33n120/05.pdf Acesso em 07/12/2020

GONZALEZ, Lélia. A categoria político-cultural de amefricanidade. In: Tempo Brasileiro. $\mathrm{n}^{\circ}$ 92/93. Rio de Janeiro, 1988.

GONZALEZ, Lélia. Lélia fala de Lélia. Revista Estudos Feministas, n. 2, Florianópolis: UFSC, 1994.

HALL, Stuart. A Identidade cultural na pós-modernidade. Rio de Janeiro: DP\&A, 2011.

HALL, Stuart. Identidade cultural e diáspora. In: Revista do Patrimônio Histórico e Artístico Nacional. $\mathrm{n}^{\circ}$. 24, IPHAN, 1996. p. 68-75.

HERBERT, Tomas. Reflexões sobre a situação teórica das ciências sociais e, especialmente, psicologia social. Tradução de Mariza V. da Silva e Laura A.P. Parisi. In: PÊCHEUX, Michel. Análise de Discurso: Michel Pêcheux. Textos escolhidos por Eni Puccinelli Orlandi. Campinas, SP: Pontes Editores, 2011 [1966]. p. 21-54.

KILOMBA, Grada. Memórias da plantação - episódios de racismo cotidiano. Rio de Janeiro: Cobogó, 2019

NEGO MAX, PRETA ARY, O rap é preto, Álbum Afrokalipse, Feat. Zudizilla,2018, Disponível em: https://www.youtube.com/watch?v=XRIYLCsO_k4 Acesso em 07/03/2020.

MIRANDA, Waldilene Silva. Diálogos possíveis: do rap à literatura marginal. Revista eletrônica Darandina. v. 4, n. 1, 2011. Disponível em: <https://www.ufjf.br/darandina/files/2011/06/Di\%c3\%a1logos-poss\%c3\%adveis-do-rap\%c3\%a0-literatura-marginal.pdf> Acesso em: 23 out. 2020.

MUNANGA, Kabengele. Negritude-usos e sentidos. Autêntica, 2015.

NASCIMENTO, Abdias do. O Quilombismo. Petrópolis: Editora Vozes, 1980. 
ORLANDI, Eni Puccinelli. As formas do silencio: no movimento dos sentidos. Campinas, S.P.: Editora da UNICAMP, 1997

ORLANDI, Eni Puccinelli. Análise de discurso: princípios e procedimentos. 7. ed. Campinas: Pontes, 2007.

PÊCHEUX, Michel. Análise Automática do Discurso (AAD-69). Trad. E. P. Orlandi. In: GADET, F.; HAK, T. Por uma Análise Automática do Discurso: uma introdução à obra de Michel Pêcheux. Campinas: Ed. da Unicamp, 1993, p. 61-105.

PIMENTEL, Spensy, Festa do rap em Sapopemba, Caros Amigos, Edição Especial, Editora Casa Amarela, São Paulo, setembro de 1998.

POSSENTI, Sírio. Os humores da língua: análises linguísticas de piadas. Campinas: Mercado de Letras, 1998.

POSSENTI, Sírio. Um caso de múltiplas rupturas. In: MUSSALIM, Fernanda; BENTES, Anna Cristina. Introdução à linguística: fundamentos epistemológicos. v. 3. 2. ed. São Paulo: Cortez, 2005. p. 351-392.

RIBEIRO, Djamila. O que é lugar de fala?. Belo Horizonte: Letramento, 2017

SAFFIOTI, Heleieth I. B. O poder do macho. São Paulo: Moderna, 1987.

AUTOR, Autor. Implementação da Lei 10.639/03: O Movimento hip hop como forma de ampliação do debate étnico-racial na educação. XXX. Trabalho de Conclusão de Curso.

SANTOS, Vitor Cei. Poesia Marginal: Lírica e Sociedade em Tempos de Autoritarismo. Literatura e Autoritarismo: Rememoração e Reminiscência, Santa Maria, n. 16, 2010.

SOUZA, Angela Maria. A caminhada é longa... e o chão tá liso: O Movimento hip-hop em Florianópolis e Lisboa, Trajetos Editorial, São Leopoldo, 2016

VAZ, Sérgio. Cooperifa: antropofagia periférica. Aeroplano, Rio de Janeiro, 2008.

WILLIAM, Rodney. Apropriação cultural. São Paulo: Pólen, 2019. Coleção Femininos Plurais. 


\title{
EI RAP es NEGRO: narrativas y discursos que nos expresan
}

\begin{abstract}
Resumen
En este trabajo pretendemos analizar las narrativas poéticas que entrelazan el hacer del rap, entendiendo que éste forma parte de los tres elementos que conforman el Movimiento Hip Hop: el rap (música), el break (baile) y el grafiti/grabado (arte gráfico). Un movimiento de expresión de las especificidades estéticas de la música, la poesía, la protesta, entre otras cosas destacando lo genuino de las producciones populares. Para este trabajo, tomaremos como ejemplo para este análisis el Rap: "O Rap É Preto" de MC Nego Max (2018), a partir de esto puntuar algunos aspectos lingüísticos, socio-históricos y políticos que se retratan en el cuerpo de la obra. Para este análisis nos servimos de estudios antropológicos, educativos y lingüístico-discursivos. Es decir, en este aspecto, destacamos la narrativa y los discursos presentes en este rap que retratan la experiencia y la escritura (Conceição Evaristo, 2014); de los MC's (Master of Ceremony); DJ's (Disc-Jockey); BGIRLS y BBOYS (que practican el break). Son los responsables de construir una conexión entre sus realidades y el público que las escucha/siente, con sus letras que abordan el racismo velado y religioso, el género y la sexualidad, el papel de la mujer negra en la sociedad y las diversas formas de entender la educación, especialmente una educación equitativa. Aun teniendo una diversidad interna en sus formas de manifestación artística y política, el Movimiento Hip-Hop desde sus raíces viene desarrollando un papel de reivindicación política y social y es sobre esta forma de manifestación artístico-cultural que la investigación aquí presentada dirige su discusión.
\end{abstract}

Palabras-claves: Movimiento Hip-Hop; Reivindicación política; Discursos; Narrativas cantadas.

\section{Le RAP est NOIR: des récits et des discours qui nous experiment}

\begin{abstract}
Résumé
Dans ce travail, nous cherchons à analyser les récits poétiques qui s'entrecroisent dans la fabrication du rap, en comprenant que cela fait partie des trois éléments qui composent le mouvement hip-hop: le rap (musique), le break (danse) et le graffiti/graffiti (art graphique). Un mouvement d'expression des spécificités esthétiques de la musique, de la poésie, de la protestation, entre autres, mettant en évidence ce qui est authentique dans les productions populaires. Pour ce travail, nous prendrons comme exemple pour cette analyse le rap: " O Rap É Preto " de MC Nego Max (2018), a partir de cela en ponctuant quelques aspects linguistiques, socio-historiques et politiques qui sont dépeints dans le corpus de l'œuvre. Pour cette analyse, nous faisons appel à des études anthropologiques, éducatives, linguistiques et discursives. C'est-à-dire, dans cet aspect, nous soulignons la narration et les discours présents dans ce rap qui dépeignent l'expérience et l'écriture (Conceição Evaristo, 2014); des MC's (Master of Ceremony); des DJ's (Disc-Jockey); des BGIRLS et BBOYS (qui pratiquent le break). Ce sont eux qui établissent un lien entre leurs réalités et le public qui les écoute ou les ressent, avec leurs textes qui abordent le racisme voilé et religieux, le genre et la sexualité, le rôle des femmes noires dans la société et les différentes façons de comprendre l'éducation, en particulier une éducation équitable. Même en ayant une diversité interne dans ses formes de manifestation artistique et politique, le mouvement Hip-Hop depuis ses racines a développé un rôle de revendication politique et sociale et c'est sur cette forme de manifestation artistique-culturelle que la recherche présentée ici oriente sa discussion.
\end{abstract}

Mots clés: Mouvement Hip-Hop; Revendication politique; Discours ; Récits chantés.

\section{The RAP is BLACK: narratives and discourses that express ourselves}

\begin{abstract}
In this paper we aim to analyze the poetic narratives that intertwine the making of rap, understanding that this is part of the three elements that make up the Hip Hop Movement: rap (music), break (dance) and graffiti / graffiti (graphic art). A movement of expressions of aesthetic, musical, poetic, and protest specificities, among others, highlighting what is genuine in popular productions. For this work, we will take as an example for this analysis the Rap: "O Rap é Preto" by MC Nego Max (2018), from this punctuating some linguistic, socio-historical and political aspects that are portrayed in the body of work. For this analysis we make use of anthropological,
\end{abstract}


RELACult - Revista Latino-Americana de Estudos em Cultura e Sociedade

Revista Latinoamericana de Estudios en Cultura y Sociedad | Revue Latino-américaine d'Études sur la culture et la société |

educational, linguistic-discursive studies. That is, in this aspect, we emphasize the narrative and the speeches present in this rap that portray the experience and writing (Conceição Evaristo, 2014); of the MC's (Master of Ceremony); DJ's (Disc-Jockey); BGIRLS and BBOYS (who practice the break). These are the ones responsible for building a connection between their realities and the listening/feeling public, with their lyrics that address veiled and religious racism, gender and sexuality, the role of black women in society, and the various ways of understanding education, especially an equitable education. Even though it has an internal diversity in its forms of artistic and political manifestation, the Hip-Hop Movement since its roots has been developing a role of political and social claim and it is on this form of artistic-cultural manifestation that the research presented here directs its discussion.

Keywords: Hip-Hop Movement, Political Claim, Discourses, Sung Narratives. 